\title{
Language, Indexicality and Gender Ideologies: Contextual Effects on the Perceived Credibility of Women
}

\author{
Erez Levon and Yang Ye
}

\begin{abstract}
It is well established that listeners' attitudes to variability in language are affected by context. One speaker's use of a particular form will not necessarily be evaluated in the same way as another's use of that same form, and the pragmatic meanings listeners associate with speech depend on the specific social setting in which that speech occurs. In this paper, we explore how this contextual sensitivity of sociolinguistic perception interacts with broader ideologies about gender. Specifically, we examine how the use of "uptalk", or rising final intonation on declarative utterances, impacts on the perceived credibility of women versus men in different legal contexts, including those characterized by strong ideologies of gender (e.g., a rape trial) and those in which that ideological framing is less pronounced (e.g., a medical malpractice trial). Our goal is to identify how social ideologies about gender affect listeners' perceptions of uptalk, and to explore the ramifications that these perceptions have on women's ability to be believed in a courtroom.
\end{abstract}

\section{Keywords}

Indexicality, perception, credibility, gender, uptalk, rape myths

In her recent book on women's voices in the public sphere, feminist theoriest Leigh Gilmore (2018:1) asserts that "judgment falls unequally on women who bear witness." Gilmore makes this claim by way of introduction to an analysis of the ways in which women's testimony women's accounts of their own experiences - are delegitimised in various public and institutional contexts. For Gilmore, the source of this delegitimation are patterns of longstanding structural and symbolic inequity (what she terms "deep reservoirs of bias") that circulate in society and that render women normatively less credible. Gilmore (2018:4-5) describes this process by noting that

Those who put forward personal accounts of suffering and those who encounter them form a transactional dynamic of testimony ... When the witness is a woman ... she will be subjected to practices of shaming and discrediting that pre-exist any specific case. 
The point Gilmore is making is that social ideologies about gender and the gendered order enable women's epistemic authority to be challenged in ways that men's understandings of their experiences are not. In this paper, we seek to examine the effects that this representational inequality has on how patterns of variation in language are interpreted, and to identify the larger ramifications of these interpretations on women's ability to be believed in specific institutional settings.

We focus on perceptions of women's versus men's speech in two distinct courtroom contexts: one in which gender ideologies play a central role (a rape trial; e.g., Ehrlich 2001, 2014; Ellison \& Munro 2008, 2009, 2013; Hildebrand-Edgar \& Ehrlich 2017) and one in which gender ideologies features less prominently (a medical malpractice trial). A courtroom setting is chosen because prior research has demonstrated that assessments of witness credibility in the courtroom are highly dependent on judgments of a witness's "character" (Brodsky et al. 2009; Neal et al. 2012) and that such judgments, in turn, often rely on dominant social stereotypes (e.g., Dixon, Mahoney \& Cocks 2002; Finch \& Munro 2004). In cases of rape and sexual assault in particular, studies have shown that judges and juries are heavily influenced by the perceived social and personality traits of victims/survivors, and by the extent to which victims/survivors are seen as conforming to dominant gender norms (Temkin \& Krahé 2008; Ellison \& Munro 2010, 2013). The linguistic feature we focus on is the use of uptalk, or rising final intonation contours on declarative utterances. A relatively new feature of London English (see Levon 2016, 2018), uptalk is characterised by strong stereotypical associations that link it to the speech of young women and a lack of authority or credibility more generally. Examining perceptions of uptalk in the speech of witnesses in a (mock) medical malpractice trial and (mock) rape trial allows us to identify how context and social ideologies about gender jointly shape listeners' perceptions of the feature, and the ramifications that such perceptions have on the credibility ascribed to women in a courtroom. 
We begin in the next section with a brief overview of relevant research in sociolinguistics that has explored the influence of language style in a courtroom context. We then turn to a review of uptalk in London, focusing on a contrast between how the feature is used by speakers in actual conversation and how it is stereotypically portrayed. We then present results from two matched-guise speaker evaluation experiments, designed to investigate the effect of uptalk on listener perceptions of witness credibility in two mock courtroom settings. We close with a general discussion of our findings.

\section{Language in the Courtroom}

Foundational work in language and the law identified different styles of speech used by witnesses in court, making a famous distinction between what has been termed more powerful and more powerless speech styles (Conley, O’Barr \& Lind 1978; Conley \& O'Barr 2005; O’Barr 1982; O’Barr \& Atkins 1980). Powerless speech styles, defined as the frequent use of particular interactional forms such as hedges and hesitation markers (e.g., um, it seems like, kind of), tag-questions (e.g., it is, isn't it?) and question intonation in declarative contexts (i.e., uptalk), were shown to be employed primarily by witnesses who were less acquainted, and hence less at ease, with the courtroom setting and those who occupied positions of lower social status. Subsequent perception research (Erickson, Lind, Johnson, \& O’Barr 1978; Bradac \& Mulac 1984; Hosman \& Wright 1987) confirmed that a witness's use of powerful versus powerless styles correlated with higher versus lower levels of perceived social attractiveness and credibility. The implication of this work is that listeners attend to linguistic form, in addition to content, when evaluating witness credibility (Giles, Wilson \& Conway 1981; Tsoudis \& Smith-Lovin 1998; Wessel et al. 2006), in stark contrast to the long-standing "referentialist" ideology of language in the courtroom, which holds that meaning resides exclusively in the content of speech rather than the manner in which that 
content is uttered (e.g., Eades, 2010; Ehrlich, 2016). That listeners rely on both form and content when evaluating speakers is unsurprising from the perspective of sociolinguistic theory. A substantial body of research has demonstrated that linguistic forms, such as uptalk, index (i.e., signal) particular personal traits (e.g., "lacking in confidence"), interactional stances (e.g., "lacking in certainty") and broader social categories (e.g., "woman") (Ochs 1992). The relationship between linguistic form and perceived indexical meaning is a highly conventionalized one. This means that there is no inherent reason why the use of uptalk, for example, is heard as sounding "powerless". Rather, the meaning emerges as the result of an ideological process links linguistic features with people who are purportedly typical users of those features, such that the presence of a "powerless" speech style, for instance, is taken as indicative of a powerless speaker (Silverstein 2003; Agha 2007; Eckert 2008).

More recent research has examined how indexical links between linguistic forms and perceived meanings interact with the broader ideologies and stereotypes that listeners bring to the courtroom. Dixon, Mahoney and Cocks (2002) investigated attributions of guilt toward a criminal suspect depending on whether he spoke with a (non-standard) Birmingham accent or a Received Pronunciation accent, the suspect's race (Black or White), and the type of crime the suspect was accused of committing (blue-collar or white-collar). They found that a Birmingham accent was associated with higher attributions of guilt and that, in an interaction between accent, suspect race and crime type, Black suspects with Birmingham accents who were accused of committing blue-collar crimes were attributed the highest levels of guilt in the sample. These finding suggest that judgments of guilt are influenced jointly by the indexical associations of accents and stereotypes about which groups (e.g., Black people) are more likely to commit a given crime. In a similar vein, Hildebrand-Edgar and Ehrlich (2017) examined the relationship between powerful speech styles in the courtroom and social ideologies about rape. They analyse a case in which a victim of sexual assault was perceived 
by jurors as being too "assertive" to be a credible victim since she used a powerful speech style when giving testimony in court. Hildebrand-Edgar and Ehrlich (2017) argue that despite the fact that a powerful speech style normally indexes heightened credibility in the courtroom, in the case of a complainant in a rape trial powerful speech can elicit the opposite effect. Taken together, these findings suggest that the indexical effects of variability in language cannot be examined in a vacuum. Rather, we must examine the effects of linguistic styles within the specific contexts in which they occur and in light of the ideologies in these contexts that govern how language and its indexical meanings are interpreted.

\section{Uptalk in London}

In line with Hildebrand-Edgar and Ehrlich's (2017) study, we seek to further understand how the relationship between language features and perceived credibility in the courtroom is filtered through ideologies of gender. Specifically, we bring additional quantitative evidence to bear on the claims made by Hildebrand-Edgar and Ehrlich (2017) in order test whether ideologies about rape and rape trials affects how listeners evaluate speech styles in the courtroom. We do this by examining perceptions of uptalk, which we define, following Warren (2016:2), as 'a marked rising intonation pattern found at the end of intonation units realised on declarative utterances'. In other words, uptalk refers to the use of what is normally considered question intonation (i.e., a final rise) on declarative statements in varieties (like London English) where this does not normally occur. ${ }^{1}$ An increasingly common feature of Englishes around the world, uptalk is normally believed to have originated in Australia in the early 1960s before spreading quickly to New Zealand and later North America (Guy et al. 1986; Britain 1992; Ching 1982). Uptalk did not arrive in Britain until at least two decades later, when it was described by Cruttenden (1986) as an incipient feature of London English, associated with what he termed "New Yuppies" (see also 
Bradford 1997). Since then, uptalk has become more prevalent throughout the London region (Arvaniti \& Atkins 2016; Barry 2008; Levon 2016, 2018), though its use has remained predominantly restricted to younger, White, and middle-class speakers.

Like in other locations where it has appeared (e.g., Warren 2016), uptalk is subject to strong social stereotypes and explicit metalinguistic commentary. These comments tend to treat uptalk as a phenomenon that is unique to young women (cf. Lakoff 1975) and that serves to undermine their seriousness, authority and credibility (e.g., Wolf 2015; for a trenchant critique of this view, see Cameron, 2015a, 2015b). These stereotypes, however, do not reflect the reality of how uptalk is actually used by speakers in the southeast of England. In an analysis of the speech of 72 young speakers of London English (ages 18-25), Levon (2016) demonstrates that both the women and the men in his sample use comparable rates of uptalk in informal interaction. In addition, and contrary to popular stereotypes, the speakers did not use uptalk in situations of uncertainty or relative powerlessness. Rather, the women were shown to use uptalk when they wished to assert their epistemic authority in conversation, particularly when their right to control the development of the conversation was under threat. Levon (2016) argues that for them, uptalk serves as a means of requesting alignment with the ongoing conversation activity (Stivers 2008) and maintaining a leading role in the interaction. The men, in contrast, used uptalk to request interactional affiliation (Stivers 2008), as a tool for involving others in the conversation, and for providing epistemic access to an evolving narrative.

The results of Levon's study demonstrate that, in actual conversation, uptalk serves a set of nuanced interactional functions (see also, e.g., Britain 1992; Guy et al. 1986 for similar arguments in other settings). This is a complex pattern that is largely lost in stereotypical beliefs about the feature. It is this mismatch between how uptalk is stereotypically perceived and how it is actually used that is our point of departure in the present paper. If a witness uses 
uptalk in a courtroom, this could be perceived in line with the feature's norms of production and interpreted as performing a nuanced interactional function (e.g., claiming epistemic authority). Alternatively, the use of uptalk could be perceived in keeping with popular stereotypes and instead be interpreted as indicating a lack of authority or epistemic certainty. We examine these two possible interpretations, and their possible interaction with gender ideologies, in the experiments described below.

\section{Experiment 1: Expert Witness Context}

The goal of the first experiment was to examine the effects of uptalk on the evaulation of witnesses in a legal setting where gender stereotypes are absent or relatively weak: expert witness testimony in a medical malpractice trial. Prior research has demonstrated that judgments of expert witness credibility tend to be robust across genders when other traits (e.g., warmth, knowledge and likeability) are controlled (e.g., Brodsky et al. 2009; Neal et al. 2012). Although no context can be said to be completely free of gendered norms or stereotypes, prior studies of language style in courtroom contexts have shown that the gender of an expert witness is only indirectly linked to listener impression formation, with the primary cue being the style of speech (i.e., powerful vs. powerless) the expert witness adopts (e.g., Erickson et al. 1978; Hosman \& Wright, 1987). Hence, the expert witness context was selected as relatively neutral testing ground for testing the effect of uptalk on listeners' evaluations of a witness.

\section{Method}

We designed a matched-guise speaker evaluation task (Lambert et al. 1960). Two speakers (one woman, one man) were recorded acting out the same extract of expert witness testimony, which was adapted from an example provided in a popular textbook on witness 
examination strategies in the courtroom (Tanford, 2010; see Appendix A). Both actors are white, university-educated speakers of Standard Southern British English who were in their late-20s at the time of recording. The two actors recorded a stimulus text containing 28 declarative intonational phrases (IPs). The actors first recorded the text with final falling intonation contours for all IPs. They then re-recorded the text with final rising intonation contours (i.e., uptalk) on seven of the 28 IPs (underlined in Appendix A). Approximating how uptalk is used in naturally-occurring speech, the seven IPs with rising intonation appeared in clusters at the beginning and end of the passage and were placed in IPs that contributed new information to the discourse. These two sets of recordings (with uptalk and without) were used to construct the experimental stimuli.

For stimuli in the uptalk condition, the final pitch phrase (i.e., from the nuclear syllable to the final IP boundary) of each of the seven target IPs was digitally manipulated in Praat for naturalness and to match the acoustic profile of typical uptalk contours in London (Levon, 2018). Manipulated IPs were then pasted into the original recordings to create "with uptalk" versions of the stimuli (one for the woman and one for the man). Figure 1 presents an example of one such manipulation. Rising contours in the uptalk condition all occurred on a single word at the rightmost edge of the final pitch phrase, and had a mean excursion size of 1.79 Equivalent Rectangular Bandwidths (ERB, a psychoacoustic measure of pitch that approximates how the human ear perceives pitch fluctuations), a mean slope of 7.17 $\mathrm{ERB} / \mathrm{second}$, and a mean duration of $261 \mathrm{msec}$. These acoustic characteristics of the rises, coupled with an overall frequency rate of $25 \%$, presented a somewhat more frequent and phonetically extreme version of uptalk than what normally occurs in naturally-occurring speech in London (see Levon 2018). This was to ensure that uptalk was prominent in the passage and so maximize the likelihood that it would be attended to by listeners. For the versions of the stimuli without uptalk, the final pitch phrase of each of the seven target IPs 
was cut and re-pasted into the original recording to ensure that both sets of stimuli (with and without uptalk) had been digitally modified. The four final audio stimuli (uptalk $\times$ speaker gender) were all between 59-65 seconds long.
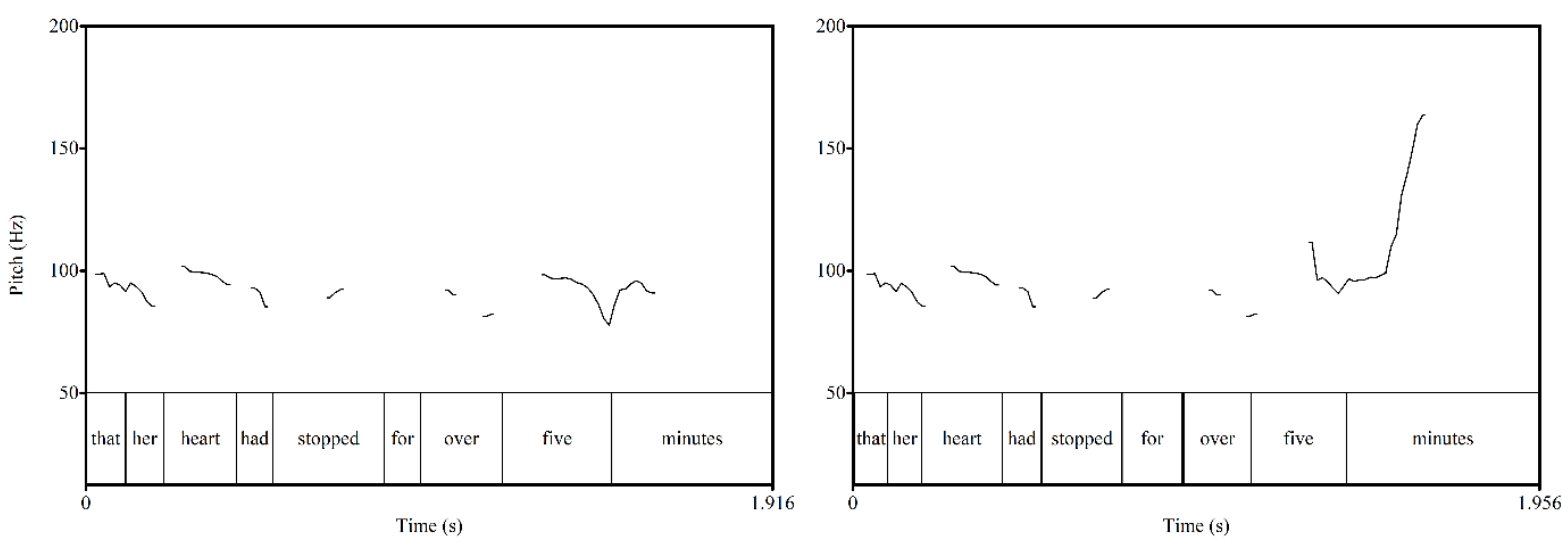

FIGURE 1. Pitch tracks of the man saying that her heart had stopped for over five minutes with falling (left) and rising (right) final intonation.

Perceived credibility of the speaker in the four audio stimuli were rated using an adapted version of the Witness Credibility Scale (WCS; Brodsky, Griffin \& Cramer, 2010), which was designed to measure juror's subjective assessments of the credibility of expert witnesses. The full version of the WCS consists of 20 semantic differential scales associated with four factors: confidence, likeability, trustworthiness and knowledge. In the present experiment, we excluded items under the knowledge factor, focusing only on perceived confidence, trustworthiness and likeability. We did so because the knowledge factor does not apply to the legal setting of the next experiment (i.e., witness testimony in a rape trial). Excluding the knowledge factor from both experiments thus maximizes comparability of listener ratings across the two experiments.

The study employed a 2 (uptalk) $\times 2$ (speaker gender) between-subjects design. The experimental task was built and delivered using Qualtrics online survey software. Respondents were recruited via Prolific, an online portal for web-based surveys. They were 
randomly assigned into one of the four conditions. After completing preliminary consent procedures, respondents were told that they would be hearing an extract of medical expert witness testimony from a medical malpractice trial, and were given some brief background information about the case (see Appendix A). They were then presented with one of the four audio recordings of testimony (woman with uptalk, woman without uptalk, man with uptalk, man without uptalk) and asked to assess the speaker's credibility on the 15 WCS items included.

After completing their ratings, respondents were asked to complete two further questionnaires before providing basic demographic information. The first questionnaire was the Ambivalent Sexism Inventory (ASI; Glick \& Fiske, 1996), which consists of items assessing two forms of sexism: hostile sexism (i.e., sexist antipathy) and benevolent sexism (i.e., a more subjectively positive form of sexism that nevertheless construes women as unequal to men). The second questionnaire was the short form of the Balanced Inventory of Desirable Responding (BIDR-16; Hart et al. 2015), which was included to assess the level of socially desirable response bias in the evaluations. On average, the entire task took 9 minutes to complete. Respondents were paid $£ 1.00$ for their participation.

There were 142 useable responses for analysis. Of these, 47 identified as men and 95 as women, with ages ranging from 18 to $66\left(\mathrm{M}_{\mathrm{age}}=36.3\right)$. All respondents were native speakers of British English currently residing in the UK. Eleven respondents reported having previously served on a jury, while 131 reported that they had not. Excluding respondents with prior jury experience had no effect on the statistical results presented below.

\section{Results}

Indices of perceived likeability, trustworthiness and confidence were created by computing the mean ratings of the 5 items per factor. ${ }^{2}$ Levels of perceived credibility among respondents 
are uniformly high, with the speakers on average (across genders) perceived as sounding very confident $(M=6.0$ out of 7$)$, trustworthy $(M=5.7)$ and relatively likeable $(M=5.2)$. Separate linear regression models were built to test the effects of witness gender (woman, man), uptalk (presence, absence) and their interaction on each of the three indices. ASI scores were included in initial models, but were shown to have no significant effects on any of the indices and so will not be discussed further. BIDR-16 scores were included as a covariate in all models to control for differences in desirable responding, though they were not shown to have a significant effect.

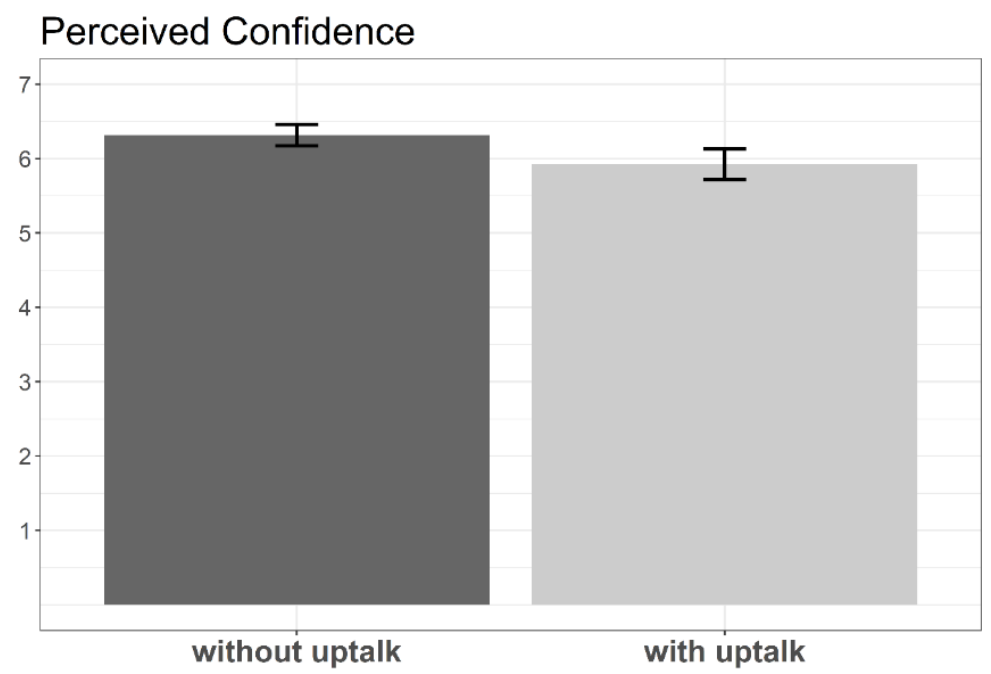

FIGURE 2. Effect of uptalk on perceived confidence of expert witnesses.

Regression analyses indicate no significant effects for gender, uptalk or their interaction for either perceived likeability (for gender, $B=0.074, t(137)=0.98, p=0.33$; for uptalk, $B=-0.005, t(137)=-0.070, p=0.94 ;$ for gender $\times$ uptalk, $B=-0.075, t(137)=0.98, p$ $=0.33$ ) or perceived trustworthiness (for gender: $B=0.051, t(137)=0.60, p=0.55$; for uptalk, $B=-0.096, t(137)=-1.14, p=0.27$; for gender $\times$ uptalk, $B=-0.038, t(137)=-0.45, p$ $=0.65)$. For perceived confidence, in contrast, there is a significant effect of uptalk $(B=0.19$, $t(137)=-3.001, p=0.003)$, though no significant effect of gender $(B=0.05, \mathrm{t}(137)=0.78, \mathrm{p}$ 
$=0.44)$ nor a significant interaction between uptalk and gender $(B=-0.04, \mathrm{t}(137)=-0.60, \mathrm{p}=$ 0.55). This indicates that the presence of uptalk correlates with a significant decrease in the perceived confidence of the witness, regardless of whether the witness is a woman or a man (see Figure 2). The effect is of medium size $(d=0.51)$ and consistent across the listener population, with regression modelling showing no significant effects of listener gender, age or, as already noted, ASI score.

\section{Discussion}

The only significant effect on perceived credibility identified was the presence versus absence of uptalk on the confidence factor, whereby the presence of uptalk led to a lowered perception of witness confidence. This is consistent with general social stereotypes about uptalk: that it signals decreased epistemic certainty or authority on the part of a speaker. It is also the opposite of how uptalk is used in actual practice by speakers in London, where previous research (Levon 2016) has shown that it serves to assert speaker rights and aid in establising a solidary conversational floor.

In interpreting this result, it is instructive to consider the specific criteria for assessing witness confidence. In the WCS, ratings of confidence are based on five items: whether the speaker sounds self-assured, confident, well-spoken, poised and relaxed. These criteria tap into participants' online perceptions of the witness at the moment of utterance, soliciting evaluations of the current performance as opposed to more durable characteristics of the speaker. This contrasts with the two other factors - trustworthiness and likeability - which focus instead on enduring personality traits such as honest, dependable, kind, and friendly. It is noteworthy that in this particular context, uptalk only influences perceptions of these more momentary, activity-bound traits, such as how poised or self-assured a witness sounds. 
The lack of a significant gender effect for any of the three credibility factors replicates patterns observed in prior research (e.g., Erickson et al. 1978; O’Barr \& Atkins 1980), which found no a priori bias in the evaluation of the credibility of expert witnesses as a function of gender. This is in line with our assumption that the legal setting we adopted here is one where gender stereotypes are less important. In the next experiment, we examine the effects of uptalk and gender in a legal setting that involves more prominent gender stereotypes.

\section{Experiment 2: Rape Trial Context}

The goal of the second experiment is to examine the effects of uptalk on witness perception in a legal setting where gender ideologies play a more prominent role: a rape trial. The work of Hildebrand-Edgar and Ehrlich (2017) shows that a rape trial can instantiate a contextspecific interpretive frame, which leads certain linguistic forms and communicative styles (e.g., speaking in an assertive or powerful fashion) to take on a new and opposing valence. As Hildebrand-Edgar and Ehrlich (2017:105) argue, "the operation of linguistic ideologies (i.e., ideologies that associate powerful/powerless speech styles with credible/non-credible speakers) is constrained by other kinds of social beliefs ... [including] the gendered ideologies that often inform decision making in sexual assault trials". Research in law about rape and sexual assault has demonstrated that adjudications of the veracity of a victim/survivor's claims are heavily influenced by beliefs about what does (and does not) constitute rape (i.e., rape myths; e.g., Brownmiller 1975; Burt 1980; Payne, Lonsway \& Fitzgerald 1999; Schwendinger \& Schwendinger, 1974) and broader ideologies of genderappropriate behaviour (e.g., how women should act and dress; Ehrlich 2001, 2014; Matoesian 2001; Trinch 2013). Therefore, the context of a rape trial provides a useful contrast to the first experiment, allowing us to examine how gender ideologies may modulate the effects of 
uptalk on witness perception and to further test Hildebrand-Edgar and Ehrlich's (2017) claims.

\section{Methods}

As in Experiment 1, the experiment used a matched-guise speaker evaluation task. The same two speakers used in Experiment 1 were recorded acting out extracts from a transcript of a rape tribunal that took place in Canada in the 1990s (Ehrlich 1998, 1999; see Appendix B). Unlike Experiment 1, the woman and the man in this experiment performed different roles, with the woman acting as the complainant and the man as the defendant. In this sense, the woman and the man adopted opposing positions in an adversarial configuration, with the testimony offered by the woman contradicting the man's and vice versa. Aside from this, all recording and audio post-processing procedures were the same as in Experiment 1: the stimulus texts each contain 28 declarative intonational phrases (IPs); the same procedure as in Experiment 1 was followed for creating "with uptalk" and "without uptalk" versions of the stimuli, where the "with uptalk" versions again presented more frequent and phonetically extreme instances of uptalk than normally occur in London. The four stimuli for Experiment 2 (role $\times$ uptalk condition) were between $62-68$ seconds long.

Listeners' ratings of perceived witness credibility were measured using the same 15item version of the WCS used in Experiment 1. We assessed listeners' gender-stereotypical beliefs about rape using the updated version of the Illinois Rape Myth Acceptance Scale (IRMA; McMahon \& Farmer 2011). IRMA is a 22-item questionnaire designed to assess respondents' endorsement of four popular rape myths: "She asked for it", "He didn't mean to", "It wasn't really rape", and "She lied". The 2011 version of IRMA is a revised version of the original IRMA scale (Payne et al. 1999), with the wording of questions updated to reflect more contemporary language use. 
The experiment employed a 2 (genders/roles: woman/complainant vs. man/defendant, between-Ss) $\times 2$ (uptalk: present vs. absent, between-Ss) $\times 2$ (order: complainant first vs. defendant first, between-Ss) $\times 2$ (evaluation target: complainant vs. defendant, within Ss) mixed design. The survey again was built and delivered using Qualtrics and respondents were recruited online via Prolific. Respondents were randomly assigned to one of the eight between-Ss conditions.

After completing preliminary consent procedures, respondents were told that they would be hearing testimony from a rape trial and were presented with some background information about the case (see Appendix B). Respondents then heard the testimony of both the complainant (woman) and the defendant (man), each of them either with or without uptalk. The order of presentation was counter-balanced, so half of the respondents heard the complainant's testimony first and half heard it second. Respondents were asked to rate the speakers' perceived credibility individually, immediately after having heard each speaker's testimony. After having rated both speakers, respondents completed two attention check questions. They were then asked to complete the ASI measure, the IRMA measure, and the BIDR-16 measure, before reporting basic demographic information. The experiment took respondents on average 12 minutes to complete. Respondents were paid $£ 1.50$ for their participation.

There were 316 useable responses. Of those, 209 identified as women and 107 as men, with ages varying from 18-73 $\left(\mathrm{M}_{\mathrm{age}}=37.3\right)$. All respondents were again native speakers of British English currently residing in the UK. Twenty-nine of them reported having served on a jury while 287 had not. Excluding respondents with prior jury experience had no effect on the statistical results. 


\section{Results}

The effect of uptalk (presence, absence), order of presentation (complainant first, defendant first) and their interaction on perceived credibility was modelled separately for the complainant and the defendant. Composite measures for perceived confidence, perceived trustworthiness and perceived likeability were devised by computing mean ratings for the five items per factor. Resulting values were entered as dependent variables in separate regression models. ${ }^{3,4}$ Preliminary examination of the data indicated that ASI scores were highly correlated with IRMA scores. Model comparisons indicated that IRMA scores provide a better overall model fit than ASI scores. ASI was therefore excluded from final modelling and will not be discussed further. Similarly, respondent gender and respondent age were never shown to have a significant effect on participant ratings, and so were excluded from final models. Scores on the BIDR-16 scale were again included as a covariate in all models to control for differences in socially desirable responding, though, once again they were not shown to have a significant effect.
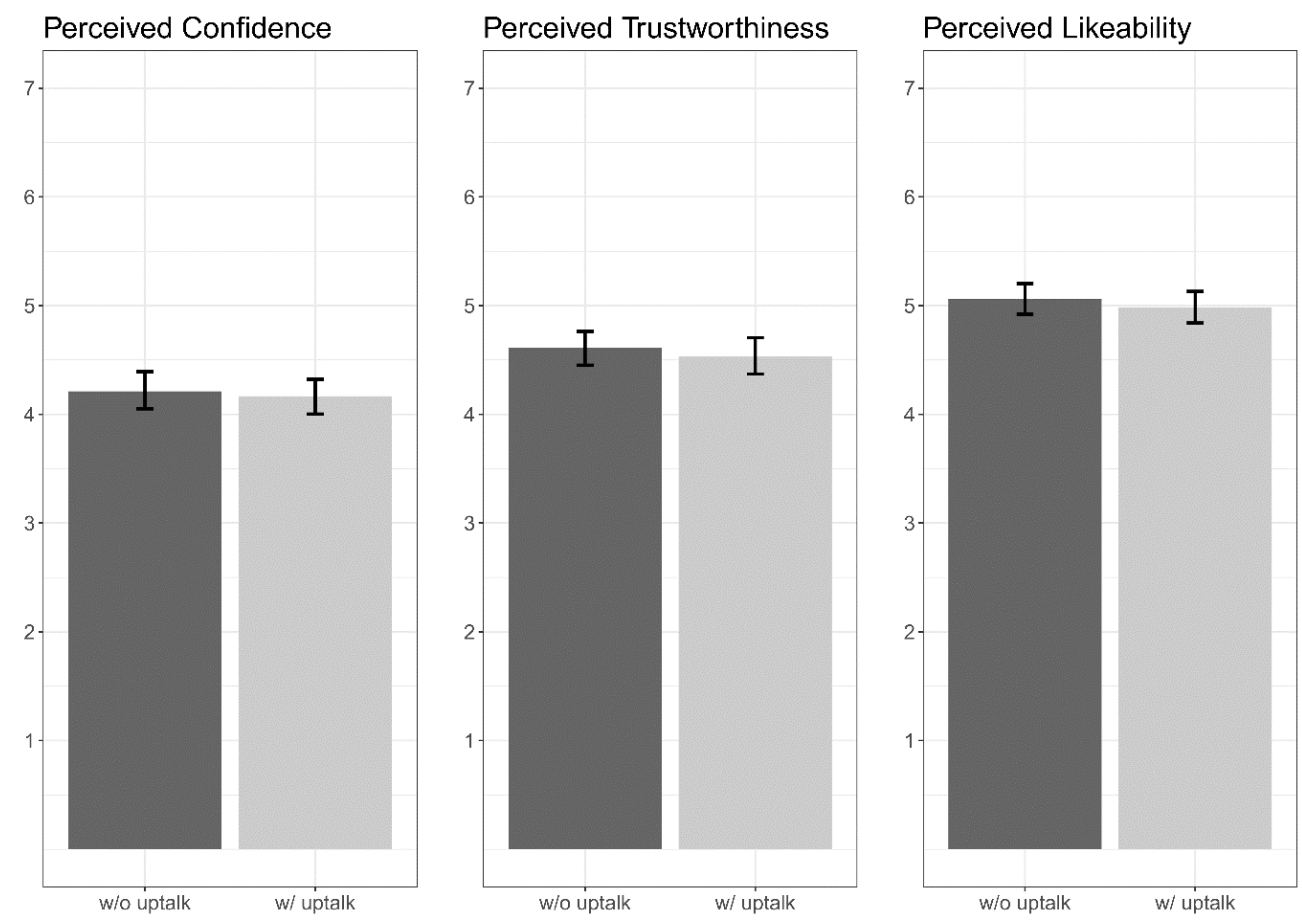

FIGURE 3. Main effect of uptalk on the perceived credibility of the complainant (woman). 
As is evident in Figure 3, uptalk has no effect on listener evaluations of the complainant across any of the three factors. Whether her testimony contains uptalk or not, listeners judged the complainant as sounding equally confident $(B=-0.02, t(308)=-0.33, p=$ $0.73)$, equally trustworthy $(B=-0.04, t(308)=-0.67, p=0.50)$ and equally likeable $(B=-$ $0.04, t(308)=-0.78, p=0.44)$. The absence of any effect of uptalk on the complainant's perceived credibility is in contrast to the uptalk effect in the expert witness context, where uptalk was shown to significantly decrease perceptions of expert witness confidence. It is also a departure from popular stereotypes that view uptalk as indicating a lack of authority and/or certainty on the part of a speaker, and particularly women. What this means is that not only is the complainant not penalized for her use of uptalk (i.e., as the expert medical witnesses were), she also does not benefit from not using uptalk. Instead, uptalk has no apparent effect on how the complainant is perceived.
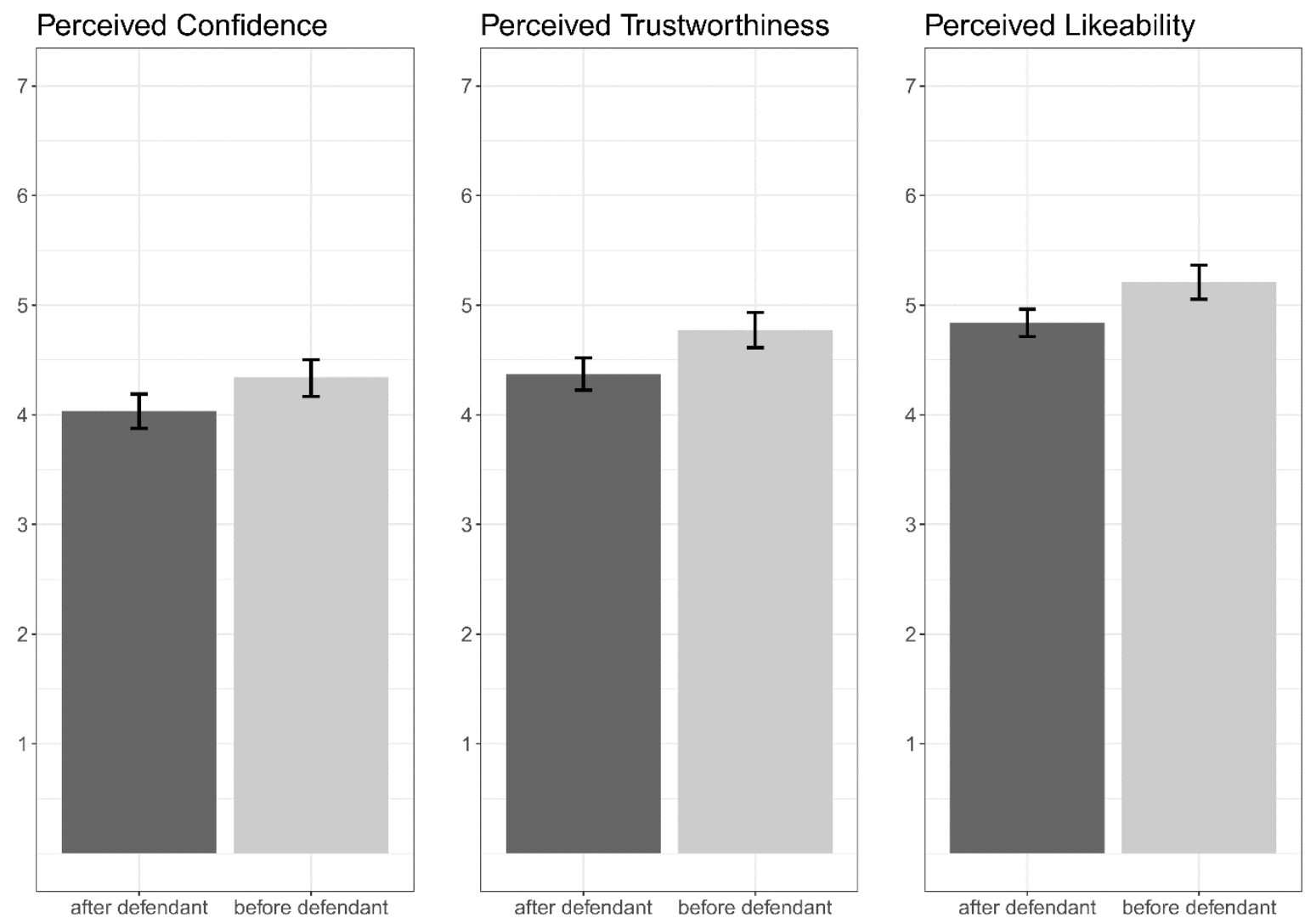

FIGURE 4. Main effect of order on perceived credibility of complainant (woman). 
There is, however, a significant effect of order on the perceived credibility of the complainant (see Figure 4). When her testimony is heard before the defendant's, the complainant is rated as sounding significantly more confident $(B=0.43, t(309)=2.99, p=$ $0.003, d=0.29)$, more trustworthy $(B=0.35, t(310)=2.63, p=0.009, d=0.40)$ and more likeable $(B=0.45, t(311)=3.64, p<0.001, d=0.41)$ than she is when heard after the defendant. At first glance, this interaction could be indicative of a simple effect of the information available at the time of evaluation. As participants evaluated witnesses immediately after hearing their testimony, those who rated the complainant after the defendant had been exposed to both points of view, while those who rated the complainant first had only been exposed to hers. Yet, this explanation fails to account for asymmetries in order effects between the complainant and the defendant. As we describe in detail below, order is not a significant predictor of evaluations of the defendant's testimony, indicating a likely gender/role-based difference in witness evaluation, such that order contributes to the evaluative profile of the complainant/woman only.

Further examination of the results revealed a significant interaction between speaker order and IRMA score on perceived confidence $(F(1,310)=4.49, p=0.035)$ and perceived likeability $(F(1,311)=4.86, p=0.028)$. In this interest of space, these interactions are illustrated with ratings for perceived likeability only in Figure 5 (the pattern for perceived confidence is similar to the one depicted in Figure 5). There, we see that the order effect holds for respondents whose scores on the IRMA scale fall within one standard deviation of the sample mean for the scale ("average"; i.e., respondents who moderately endorse rape myths, $\mathrm{N}=190$ ), as well as for those whose scores are less than one standard deviation below the sample mean ("low"; i.e., respondents who largely do not endorse rape myths, $\mathrm{N}=65$ ). Respondents in these two groups rated the complainant as sounding significantly less confident and less likeable when she was heard after the defendant. In contrast, respondents 
whose scores on the IRMA scale are greater than one standard deviation above the sample mean ("high"; i.e., respondents who largely endorse rape myths, $\mathrm{N}=61$ ) showed no such distinction: they rated the complainant's perceived confidence and perceived trustworthiness at similar levels regardless of whether her testimony was heard first (i.e., without having heard the defendant's testimony) or second (i.e., after having heard the defendant's testimony).

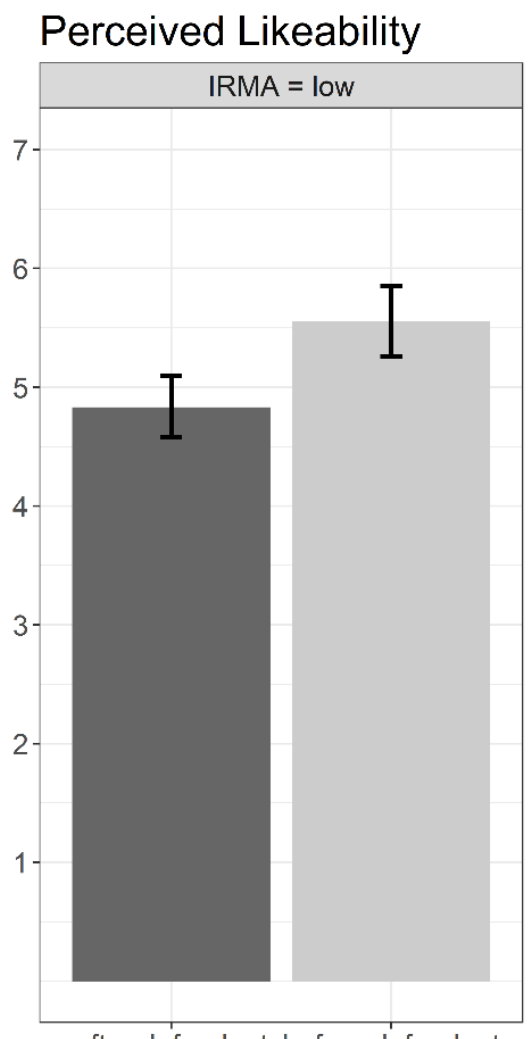

after defendant before defendant

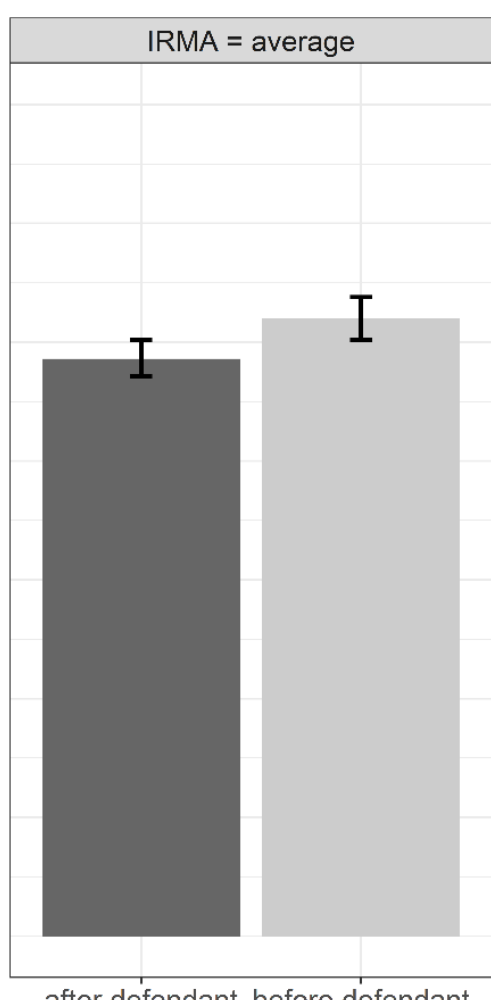

after defendant before defendant

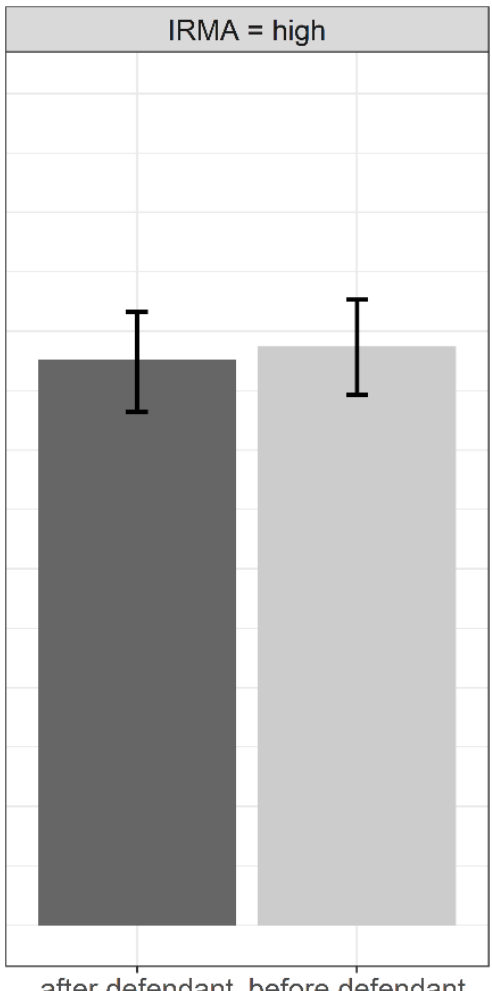

after defendant before defendant

FIGURE 5. Interaction of order and IRMA score on perceived likeability of complainant (woman).

Results for perceptual evaluations of the defendant reveal a very different pattern. As shown in Figure 6, uptalk had a significant effect on the perceived likeability $(B=0.17$, $\mathrm{t}(311)=3.19, \mathrm{p}=0.002, d=0.32)$ and the perceived trustworthiness $(B=0.12, \mathrm{t}(311)=2.24$, $\mathrm{p}=0.03, d=0.22)$ of the defendant. Interestingly, respondents judged the defendant as sounding more likeable and trustworthy when his testimony contained uptalk than when it did 
not. In addition to the effect of uptalk, there was also an significant effect of IRMA score in predicting the defendant's perceived likeability $(B=0.26, t(311)=4.95, p<0.001)$ and perceived trustworthiness $(B=0.27, t(311)=5.29, \mathrm{p}<0.001)$. For both factors, higher IRMA scores - indicating higher levels of endorsement of popular rape myths - correlate with more positive evaluations of the defendant. Crucially, no interaction effect between uptalk and IRMA score was found: for likeability, $F(1,31)=1.04, p=0.31$; for trustworthiness, $F(1,31)$ $=0.001, p=0.97$ (see Figure 7). Finally, as mentioned earlier, there is no significant main effect or interaction effect $(p>0.516)$ involving order of presentation for any of the factors. Unlike for the complainant, whether the defendant's testimony is heard first (i.e., without having heard the complainant's testimony) or second (i.e., after having heard the complainant's testimony) appears to have no bearing on his perceived credibility.
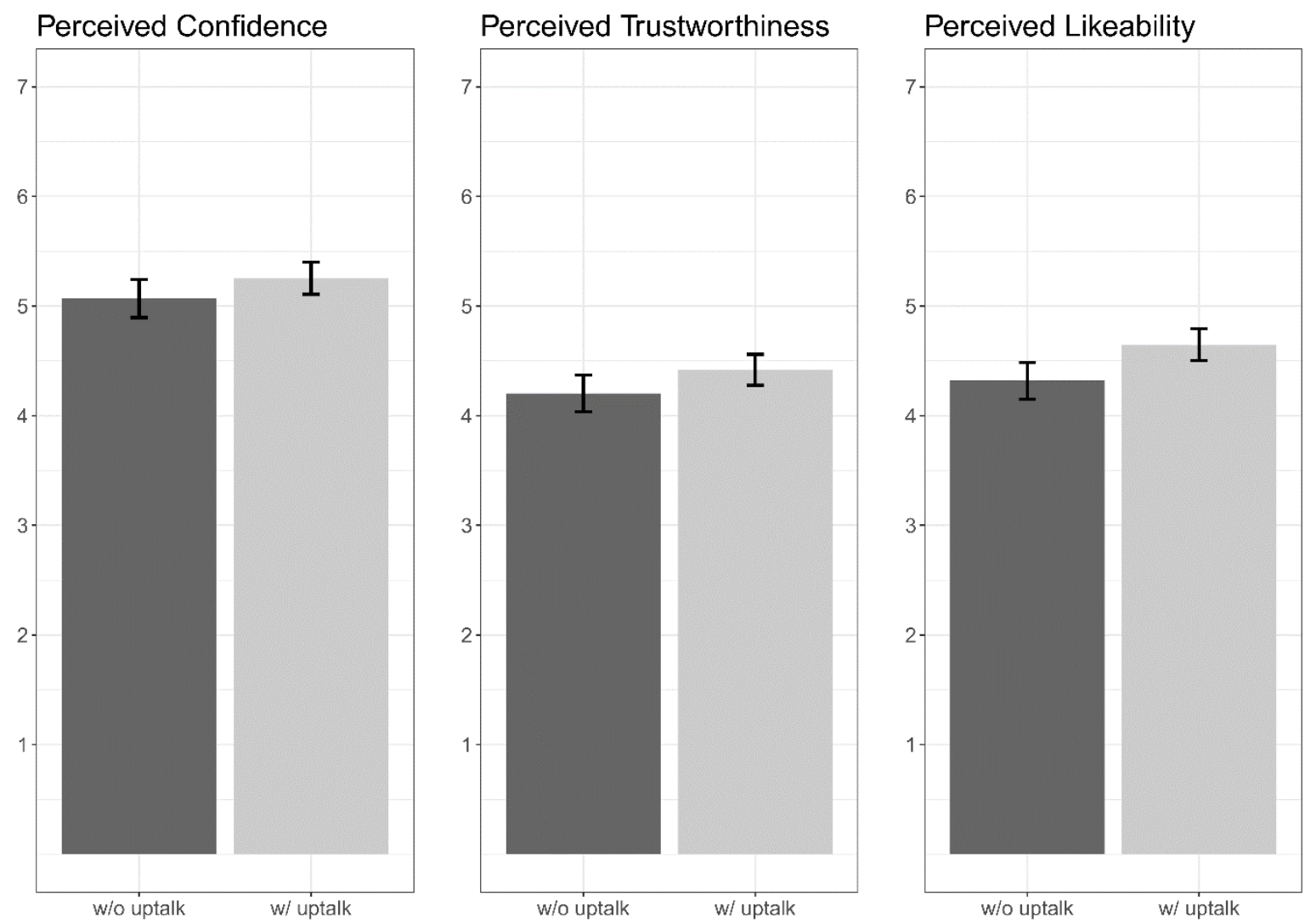

FIGURE 6. Main effect of uptalk on perceived credibility of the defendant (man). 

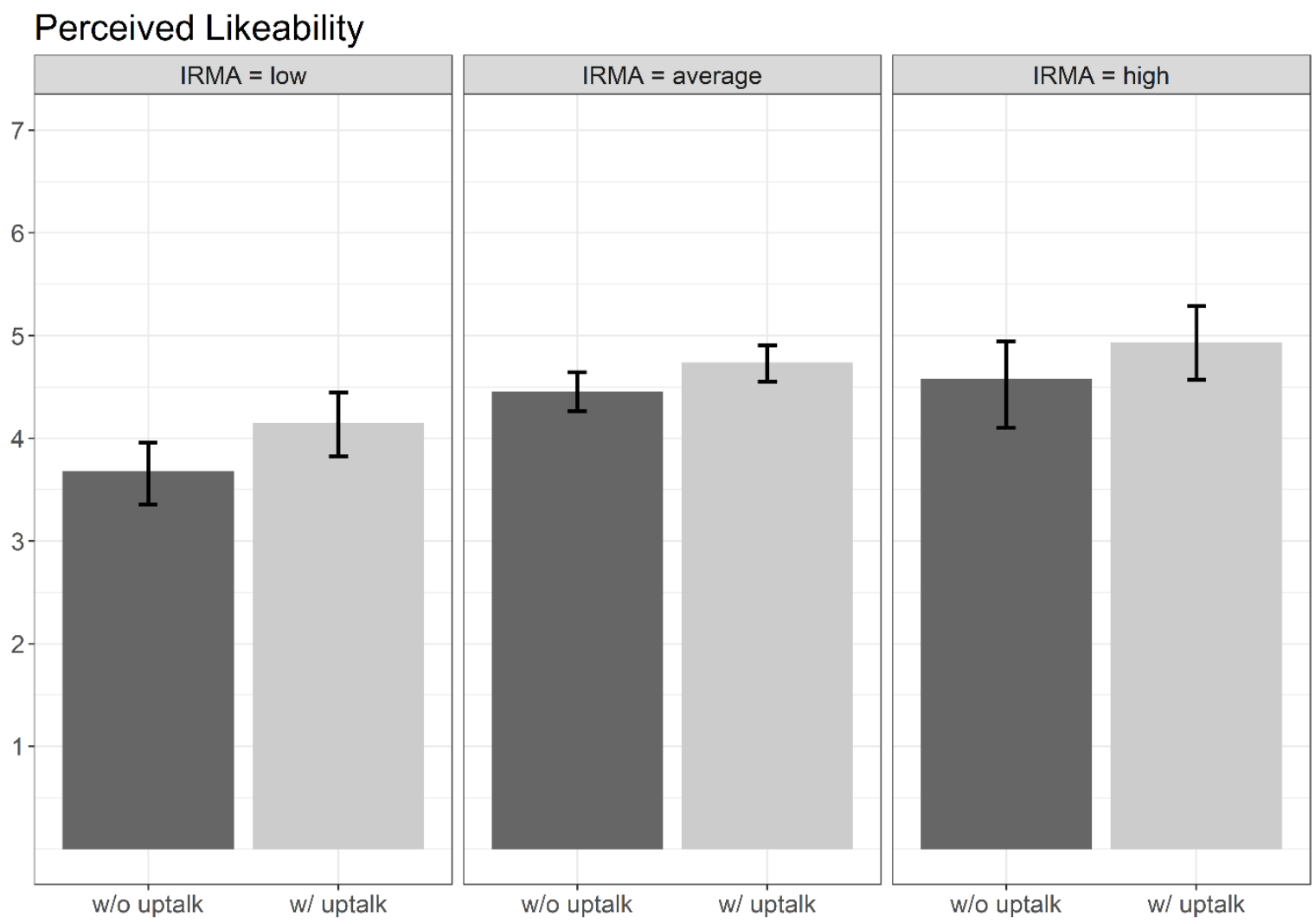

FIGURE 7. Independent effects of uptalk and IRMA score on perceived likeability of the defendant (man).

\section{Discussion}

The findings indicate two distinct and complex evaluative profiles in the ratings of the credibility of the complainant and the defendant in a rape trial context. For the defendant, uptalk correlates with increased perceptions of likeability and trustworthiness. This finding suggests that in a rape trial context, uptalk increases perceived social attractiveness of the defendant. This is inconsistent with stereotypical beliefs about uptalk and with the results of Experiment 1, but is in line with prior findings on how men use uptalk in naturally-occurring conversation in London. In previous work, Levon (2016) argues that young men in London deploy uptalk in conversation to fulfil a referential function of highlighting new and/or interesting pieces of information as a way of asserting sociality rights (Spencer-Oatey 2000) and requesting interactional affiliation (Stivers 2008). In other words, uptalk was used by men to encourage others to include them in the interaction, which subsequently leads to an 
increase in their social attractiveness as perceived by the others. It appears that for respondents of this experiment, the defendant's use of uptalk was interpreted as performing this kind of function.

For the complainant, uptalk has no effect on her perceived credibility. Instead, we find a significant order effect: when the complainant's testimony is heard after the defendant's, she is perceived as sounding less credible as compared to when respondents heard her testimony first. No such order effect was observed for the defendant. In addition, the effect of order on the complainant's perceived credibility is significantly conditioned by respondents' IRMA score. For respondents who strongly endorse popular rape myths (i.e., those who score most highly on the IRMA scale), order has no effect (see Figure 5). This appears to suggest that while some respondents (those with "low" and "average" IRMA scores) were willing to give the complainant the benefit of the doubt (when she was heard before the defendant), those who more highly endorse popular rape myths were not. This interpretation is in line with the observed positive correlation between IRMA scores and the perceived credibility of the defendant, potentially indicating that endorsement of rape myths is associated with a predisposition to favour a defendant's perspective in a rape trial.

Overall, the above findings demonstrate qualitative differences in how the woman/complainant versus the man/defendant is perceived - differences that we would argue are grounded in the gendered ideologies of the rape trial context. First, while the defendant is eligible to have his credibility enhanced by uptalk, the same option does not seem to be available for the complainant. Whether the complainant uses uptalk or not has no bearing on her perceived credibility. Second, while uptalk has no effect, the complainant's credibility is nevertheless subject to questioning and is significantly undermined by the defendant's testimony, whereas the defendant's credibility is not undermined in this way. Finally, while the defendant is helped by dominant popular ideologies regarding gender and rape (as shown 
in the positive correlation between IRMA score and perceived credibility), the complainant is hindered by them. It is therefore clear that in the rape trial context, the woman/complainant and the man/defendant are subject to unequal interpretive constraints. We turn to this point in our general discussion.

\section{General Discussion}

In two experiments, we examined the effects of a particular speech feature - uptalk - on the perceptions of witness credibility in two mock courtroom contexts. The presence of uptalk in witness testimony leads to different effects on witness evaluations across the two contexts and, in the case of the rape trial, across the two speakers. These results are important both for our understanding of how listeners ascribe meaning to conversational features like uptalk, and for developing a fuller picture of the ways that gender ideologies constrain the interpretive frames that are available in different types of legal settings.

We begin with the first of these two issues. In a recent discussion of what she terms assertive rising declaratives, Jeong (2018) provides a formal semantic definition of utterances with uptalk contours. Like all declarative utterances (i.e., those with both rising and falling intonation), Jeong argues that declaratives with uptalk assert a proposition $p$, in effect placing $p$ on the conversational "table" (or the set of issues raised in a particular interaction; e.g., Farkas \& Bruce, 2010). In addition, uptalk declaratives also communicate that there is a particular pragmatic issue in relation to $p$. This is what distinguishes a declarative utterance with falling intonation, which simply asserts $p$, from one with rising intonation, which asserts $p$ but also makes some related pragmatic concern relevant to the interaction. Crucially, the interpretation of what that specific pragmatic issue is depends on the context in which the rising contour is heard, as well as on the social backgrounds, experiences and psychological predispositions of the listeners. 
Jeong's (2018) formal model provides an elegant framework for capturing the different context effects of uptalk reported in the two experiments. In both cases, differences in evaluation between the uptalk and no uptalk conditions can be taken as evidence that uptalk is interpreted by listeners as raising some pragmatic issue related to the propositional content that is asserted. In the expert witness context, this issue is understood by listeners as communicating something about the speaker's epistemic (un)certainty, resulting in a significant decrease in perceptions of witness confidence. Put simply, listeners might interpret uptalk in the speech of expert witnesses as communicating something like 'I think this is correct, but I'm not entirely sure'. For the defendant in the rape trial, in contrast, the pragmatic issue signalled by uptalk is interpreted differently. Here, the finding that listeners perceive the defendant in the uptalk condition as sounding significantly more likeable and more trustworthy seems to indicate that the pragmatic issue in question is interpreted as relating to Gricean maxims of relevance, quantity and/or manner (Westera 2013): 'Is this the kind of information you want? Is this enough information? Is this the right format for the information?' The presence of these pragmatic queries takes on a second-order meaning related to the defendant himself, i.e., as someone who cares about how his message is being received. It would then be this second-order interpretation (or index) that causes the observed increase in the defendant's perceived likeability and trustworthiness: by using uptalk to signal his concern for pragmatic rules of interaction, the defendant is perceived as a more socially attractive person.

In short, we argue that the difference in results across the two mock courtroom contexts derives from differences in the specific pragmatic issue that uptalk is taken to index. The expert witness context forces an interpretive focus on message content, leading to an interpretation of the uptalk-linked pragmatic issue as related to the speaker's epistemic certainty about the message itself. The rape trial context instead forces a focus on the 
personality traits of the speaker more broadly. This leads to the second-order evaluation of uptalk as related to the defendant's social attractiveness. While the precise pragmatic mechanism that causes these differences in interpretive focusing across contexts remains to be elaborated, findings from the present research support the argument that such a difference exists and that it can account for the distinct evaluations of uptalk that we observe in the two experiments.

Moreover, we suggest that the proposed difference in the focus of interpretation across contexts can help us to understand the role of gender stereotypes in accounting for the patterns of evaluation we observe. Recall that in the expert witness context, a lack of uptalk led to perceptions of increased credibility of the woman (and the man). In sharp contrast, no such effect is observed for the woman/complainant in the rape trial context. What causes this difference across the two experiments? We argue that this difference is due to the strength of normative gendered ideologies that dictate how credible a rape victim is taken to be in the context of a rape trial, such that linguistic markers of enhanced credibility (such as the lack of uptalk in her speech) are rendered indexically inoperative in this context. In a medical malpractice trial, by contrast, such ideologies of gender are less prominent, allowing linguistic indexes of credibility (like uptalk) to influence listener perceptions. In other words, we argue that our findings support Hildebrand-Edgar and Ehrlich's (2017) assertion that gender ideologies interact with and contrain the indexical potential of linguistic features, affecting the extent to which women are able to use indexicality to their benefit in different situations.

Prior research in linguistics and related fields has demonstrated that patriarchal assumptions about gender and sexual practice predispose judges and juries to adopt different standards in evaluating the perceived credibility of women versus men in cases of rape and sexual assault (e.g., Caringella, 2009; Ehrlich, 2001; Hildebrand-Edgar \& Ehrlich, 2017; 
Tiersma, 2007). As summarised succinctly by Gilmore (2018:20), "women encounter doubt as a condition of bearing witness". In the current study, we argue that a societal predisposition to discredit women makes it such that in the rape trial context - where, as we argue, interpretive focus in placed on the speaker rather than the message - the complainant is unable to benefit from positive second-order evaluations of using uptalk (as the defendant does) nor is she able to benefit from the positive evaluations associated with not using uptalk (as she does in the medical malpractice trial). Instead, the complainant's credibility is subject to the overriding doubt inherent in normative gender ideologies that Gilmore describes- a doubt that accounts both for the lack of an uptalk effect and for the presence of order effects. Through the present research, we therefore hope to have demonstrated that how uptalk is interpreted does not depend exclusively on the context in which it is heard and evaluated. It also depends on the ways in which gender ideologies constrain who has the authority to speak, to be heard and to be believed in different contexts.

\section{Notes}

1 We exclude cases where rising final intonation is the default pattern, such as in many urban Northern varieties of British English (e.g., Belfast, Liverpool, Glasgow; see Cruttenden 1994), as well as continuation rises.

2 Reliability and construct validity analyses of the factors support the creation of these indices.

3 Once again, reliability and construct validity analyses support the creation of these composite indices.

4 Note that there are general differences in how the complainant versus the defendant were evaluated overall, with the defendant generally perceived as more confident (mean value of 5.16 vs. 4.19 for the complainant), though the complainant was generally heard as more likeable (5.02 vs. 4.49 for the defendant) and more trustworthy (4.57 vs. 4.31 for the defendant). The overall mean values, however, mask a great deal of internal variability in evaluations and ignore the fact that different external factors (e.g., uptalk, speaker order) effect judgments of the complainant versus the defendant, as described in the discussion.

\section{References}

Agha, Asif (2007). Language and social relations. Cambridge: Cambridge University Press. 
Arvaniti, Amalia \& Atkins, Madeleine (2016). Uptalk in Southern British English. In Jon Barnes, Alejna Brugos, \& Stefanie Shattuck-Hufnagel (eds.), Proceedings of Speech Prosody 8, 153-57. Boston: Boston University.

Barry, Angela (2008). The form, function and distribution of high rising intonation in Southern California and Southern British English. Saarbrucken: VDM Verlag Dr Muller.

Bradac, James \& Mulac, Anthony (1984). A molecular view of powerful and powerless speech styles: Attributional consequences of specific language features and communicator intentions. Communication Monographs 51(4):307-19.

Bradford, Barabara (1997). Upspeak in British English. English Today 13(3):29-36.

Britain, David (1992). Linguistic change in intonation: The use of High Rising Terminals in New Zealand English. Language Variation and Change 4:77-104.

Brodsky, Stanley; Griffin, Michael; \& Cramer, Robert (2010). The Witness Credibility Scale: An outcome measure for expert witness research. Behavioral Sciences \& the Law 28(6):892-907.

Brodsky, Stanley; Neal, Tess; Cramer, Robert; \& Ziemke, Mitchell (2009). Credibility in the courtroom: How likeable should an expert witness be? Journal of the American Academy of Psychiatry and the Law 37(4):525-32.

Brownmiller, Susan (1975). Against our will: Men, women and rape. New York: Simon \& Schuster.

Burt, Martha (1980). Cultural myths and supports for rape. Journal of Personality and Social Psychology 38(2):217-30.

Cameron, Deborah (2015a). A response to Naomi Wolf. langauge: a feminist guide. Online: https://debuk.wordpress.com/2015/07/26/a-response-to-naomi-wolf/; accessed 17 December 2018.

Cameron, Deborah (2015b). Just don't do it. language: a feminist guide. Online: https://debuk.wordpress.com/2015/07/05/just-dont-do-it/; accessed 17 December 2018.

Caringella, Susan (2009). Addressing rape reform in law and practice. New York: Columbia University Press.

Ching, Marvin (1982). The question intonation in assertions. American Speech 57(2):95-107.

Conley, John \& O’Barr, William (2005). Just words: Language and power, 2nd ed. Chicago: University of Chicago Press.

Conley, John; O’Barr, William; \& Lind, E. Allan (1978). The power of language: Presentational style in the courtroom. Duke Law Journal 1375-1400.

Cruttenden, Alan (1986). Intonation. Cambridge: Cambridge University Press.

Dixon, John; Mahoney, Berenice; \& Cocks, Roger (2002). Accents of guilt? Effects of regional accent, race and crime type on attributions of guilt. Journal of Language and Social Psychology 21(2):162-68.

Eades, Diana (2010). Sociolinguistics and the legal process. Bristol: Multilingual Matters.

Eckert, Penelope (2008). Variation and the indexical field. Journal of Sociolinguistics 12(4): 453-76.

Ehrlich, Susan (1998). The discursive reconstruction of sexual consent. Discourse \& Society 9(2):149-71.

Ehrlich, Susan (1999). Communities of practice, gender, and the representation of sexual assault. Language in Society 28(2):239-56.

Ehrlich, Susan (2001). Representing rape: Language and sexual consent. New York: Routledge.

Ehrlich, Susan (2014). Language, gender and sexual violence: Legal perspectives. In Susan Ehrlich, Miriam Meyerhoff, \& Janet Holmes (eds.), Handbook of language, gender and sexuality, 452-70. Oxford: Wiley-Blackwell. 
Ehrlich, Susan (2016). Post penetration rape: Coercion or freely given consent. In Susan Ehrlich, Diana Eades, \& Janet Ainsworth (eds.), Discursive constructions of consent in the legal process, 47-70. Oxford: Oxford University Press.

Ellison, Louise \& Munro, Vanessa (2008). Reacting to Rape: Exploring Mock Jurors' Assessments of Complainant Credibility. British Journal of Criminology 49(2):202-19. Online: https://academic.oup.com/bjc/article-lookup/doi/10.1093/bjc/azn077; accessed 2 July 2019.

Ellison, Louise \& Munro, Vanessa (2009). Of 'Normal Sex' and 'Real Rape': Exploring The Use of Socio-Sexual Scripts in (Mock) Jury Deliberation. Social \& Legal Studies 18(3):291-312.

Ellison, Louise \& Munro, Vanessa (2010). A Stranger in the Bushes, or an Elephant in the Room? Critical Reflections Upon Received Rape Myth Wisdom in the Context of a Mock Jury Study. New Criminal Law Review 13(4):781-801.

Ellison, Louise \& Munro, Vanessa (2013). Better the Devil You Know? 'Real Rape' Stereotypes and the Relevance of a Previous Relationship in (Mock) Juror Deliberations. The International Journal of Evidence \& Proof 17(4):299-322.

Erickson, Bonnie; Lind, E.Allan; Johnson, Bruce C; \& O’Barr, William M (1978). Speech style and impression formation in a court setting: The effects of "powerful" and "powerless" speech. Journal of Experimental Social Psychology 14(3):266-79.

Farkas, Donka \& Bruce, Kim (2010). On reacting to assertions and polar questions. Journal of Semantics 27(1):81-118.

Finch, Emily \& Munro, Vanessa (2004). Juror Stereotypes and Blame Attribution in Rape Cases Involving Intoxicants: The Findings of a Pilot Study. British Journal of Criminology 45(1):25-38.

Giles, Howard; Wilson, Pamela; \& Conway, Anthony (1981). Accents and lexical diversity as determinants of impression formation and perceived employment suitability. Language Sciences 3(1):91-103.

Gilmore, Leigh (2018). Tainted witness: Why we doubt what women say about their lives. New York: Columbia University Press.

Glick, Peter \& Fiske, Susan (1996). The Ambivalent Sexism Inventory: Differentiating hostile and benevolent sexism. Journal of Personality and Social Psychology 70(3):491512.

Guy, Gregory; Horvath, Barbara; Vonwiller, Julia; Daisley, Elaine; \& Rogers, Inge (1986). An intonational change in progress in Australian English. Language in Society 15(1):2352.

Hart, Claire; Ritchie, Timothy; Hepper, Erica; \& Gebauer, Jochen (2015). The Balanced Inventory of Desirable Responding Short Form (BIDR-16). SAGE Open 5(4).

Hildebrand-Edgar, Nicole \& Ehrlich, Susan (2017). "She was quite capable of asserting herself": Powerful speech styles and assessments of credibility in a sexual assault trial. Language and Law 4(2):89-107.

Hosman, Lawrence A. \& Wright, John W. (1987). The effects of hedges and hesitations on impression formation in a simulated courtroom context. Western Journal of Speech Communication 51(2):173-88.

Jeong, Sunwoo (2018). Intonation and sentence type conventions: Two types of rising declaratives. Journal of Semantics 35(2):305-56.

Lakoff, Robin (1975). Langauge and woman's place. Cambridge: Cambridge University Press.

Lambert, W E; Hodgson, R C; Gardner, R C; \& Fillenbaum, S (1960). Evaluational reactions to spoken languages. Journal of abnormal and social psychology 60(1):44-51.

Matoesian, Gregory (2001). Law and the language of identity: Discourse in the Kennedy 
Smith rape trial. Oxford: Oxford University Press.

McMahon, Sarah \& Farmer, G. Lawrence (2011). An updated measure for assessing subtle rape myths. Social Work Research 35(2):71-81.

Neal, Tess; Guadagno, Rosanna; Eno, Cassie; \& Brodsky, Stanley (2012). Warmth and competence on the witness stand: Implications for the credibility of male and female expert witnesses. Journal of the American Academy of Psychiatry and the Law 40(4):488-97.

O'Barr, William (1982). Linguistic evidence: Power and strategy in the courtroom. New York: Academic Press.

O’Barr, William \& Atkins, Bowman (1980). 'Women's language' or 'powerless language'. In Sally McConnell-Ginet, Ruth Borker, \& Nelly Furman (eds.), Women in language and society, 93-109. New York: Praeger.

Ochs, Elinor (1992). Indexing gender. In Alessandro Duranti \& Charles Goodwin (eds.), Rethinking context: Language as an interactive phenomenon, 335-58. Cambridge: Cambridge University Press.

Payne, Diana; Lonsway, Kimberly; \& Fitzgerald, Louise (1999). Rape myth acceptance: Exploration of its structure and its measurement using the Illinois Rape Myth Acceptance Scale. Journal of Research in Personality 33(1):27-68.

Schwendinger, Julia \& Schwendinger, Herman (1974). Rape myths: In legal, theoretical, and everyday practice. Crime and Social Justice 1(1):18-26.

Silverstein, Michael (2003). Indexical order and the dialectics of sociolinguistic life. Language \& Communication 23(3-4): 193-229.

Spencer-Oatey, Helen (2000). Rapport management: A framework for analysis. In Helen Spencer-Oatey (ed.), Culturally speaking: Managing rapport through talk across cultures, 11-46. London: Continuum.

Stivers, Tanya (2008). Stance, alignment and affiliation during storytelling: When nodding is a token of affiliation. Research on language and social interaction 41(1):31-57.

Tanford, J. Alexander. (2010). The trial process: Law, tactics \& ethics. Durham: Carolina Academic Press.

Temkin, Jennifer \& Krahé, Barbara (2008). Sexual Assault and the Justice Gap : A Question of Attitude. Oxford: Hart Publishing.

Tiersma, Peter (2007). The language on consent in rape law. In Janet Cotterill (ed.), The language of sexual crime, 83-103. Basingstoke: Palgrave Macmillan.

Trinch, Shonna (2013). Recalling rape: Moving beyond what we know. In Chris Heffer, Frances Rock, \& John Conley (eds.), Legal-lay communication: Textual travels in the law, 288-306. Oxford: Oxford University Press.

Tsoudis, Olga \& Smith-Lovin, Lynn (1998). How Bad Was It? The Effects of Victim and Perpetrator Emotion on Responses to Criminal Court Vignettes. Social Forces 77(2):695.

Warren, Paul (2016). Uptalk: The phenomenon of rising intonation. Cambridge: Cambridge University Press.

Wessel, Ellen; Drevland, Guri C. B.; Eilertsen, Dag Erik; \& Magnussen, Svein (2006). Credibility of the Emotional Witness: A Study of Ratings by Court Judges. Law and Human Behavior 30(2):221-30.

Westera, Matthijs (2013). Attention, I'm violating a maxim!: A unifying account of the final rise. , 17th Workshop on the Semantics and Pragmatics of Dialogue (SemDial), 1-10.

Wolf, Naomi (2015). Young women, give up on the vocal fry and reclaim your strong female voice. The Guardian. Online:

https://www.theguardian.com/commentisfree/2015/jul/24/vocal-fry-strong-female-voice. 


\section{Appendix A}

Instructions and Extract of Witness Testimony for the Expert Witness Context (adapted from Tanford 2010). Underlined words were manipulated between the uptalk/no uptalk conditions. '/ indicates Intonational Phrase breaks.

\section{Instructions}

In the following section, you will hear testimony provided by an expert witness in a medical malpractice trial. In the case, a surgeon and an anaesthesiologist are accused of negligence in their handling of complications that arose during a routine procedure. These complications resulted in the patient suffering permanent brain damage. The patient's family asserts that the brain damage could have been prevented had the surgeon and the anaesthesiologist not been negligent. The doctors claim to have done everything in their power to prevent the brain damage.

On the next page, you will hear an audio recording of part of the testimony given by an expert medical witness in the trial. In the recording, the witness provides an expert opinion about what might have happened during the surgery, as per available evidence, and who is responsible for the patient's brain damage.

Your task is to listen to the testimony very carefully and form an impression about the witness based on what you hear. After listening to the testimony, you will be asked to give your opinions about the witness based on what you have heard.

Please listen to the testimony very carefully: At a later point in the study, you will be asked to remember some details about what the witness said.

\section{Testimony}

The patient suffered cardiac arrest while in the operating theatre./ Apparently, she coughed up something into her surgical mask./ And that stopped her breathing./ When she coughed it up, it blocked the flow of air/ and she couldn't breathe properly./ So the concentration of anaesthesia in her blood got too high/ and her heart stopped./ When the heart stops, the brain is deprived of oxygen./ And you get brain damage./ That's why she's in the state she's in today./ Now/ The doctors say that it took them three to four minutes to restore the heartbeat./ In my opinion, that's not accurate./ There's too much brain damage./ It must have taken much longer./ I would say nine or ten minutes./ And by then it was too late./ Overall, I think the care provided fell way below minimum standards./ Way below./ There's always a danger that a patient will cough up during surgery./ But no one noticed that happening./ If they had, they could have cleared the airway/ And everything would have been fine. After that, no one noticed that her heart had stopped./ The amount of brain damage indicates no heartbeat for around ten minutes./ If, as the doctors say, it took three to four minutes to restore the heartbeat/ That means no one noticed that her heart had stopped for over five minutes./ And that is simply unacceptable./ 


\section{Appendix B}

Instructions and Extracts of Testimony from the Complainant and the Defendant in the Rape Trial Context (adapted from Ehrlich 1998, 1999). Underlined words were manipulated for the uptalk/no uptalk conditions. '/' indicates Intonational Phrase breaks.

\section{Instructions}

In the following section, you will hear testimony provided by parties to a sexual assault trial.

In the case in question, Marg (the complainant) has charged that Matt (the defendant) sexually assaulted her one night in her university accommodation. Marg asserts that she invited Matt to her room that night and that he allegedly persisted in unwanted sexual behaviour. Matt claims, in contrast, that the sexual activity was consensual.

You will hear testimony given by both Marg and Matt, and will be asked to give your opinions about each of them based on what you hear.

Please listen to their testimony very carefully: At one point in the study, you will be asked to remember some details about what they have said.

\section{Complainant Testimony}

I kept saying 'let's just go to sleep'./ I didn't honestly know what else in my mind to do at that time./ For me that was all I could do to tell him I didn't want to do anything./ He made me feel like I wasn't saying anything/ that I wasn't saying 'no'./ And I was afraid./ I was extremely afraid of being hurt./ So I tried different approaches./ And in my mind I hoped that they were getting through./ But they were being ignored./ I tried/ I mean/ maybe they weren't being ignored/ I don't know why he didn't listen./ But I was making it as clear as I could./ Like, I told Matt/ I said if the circumstances would have been different/ maybe./ It was a lie/ but I mean it was another way for me to try to tell him 'no'./ I mean obviously I just wanted to go to sleep./ And I kept telling him/ I kept telling him/ I was afraid to ask him to sleep on the floor./ It crossed my mind/ but I didn't want to get hurt./ I didn't want to get into a big fight./ I just wanted to go to sleep and forget about the whole entire night./

\section{Defendant Testimony}

She was like caressing/ and like we were fooling around/ and I was caressing her and everything./ And for her to say that I was taking advantage of her/ when she let me kiss her/ when she never said 'no'/ when she never said 'stop '/ when she never got up out of the bed./ Uh for her to go/ for her just to say uh you know/ 'I couldn't do anything and I was just lying there '/ and uh/ and then sort of like/ she can't do anything/ and then she goes and says to people/ 'Matt took advantage of me'/ and then, and then after saying that/ she gets back into bed with me./ I mean, if somebody takes advantage/ if I was, if I was a woman/ and I was in bed with somebody/ and this person started to take advantage of me and was doing things I didn't want to do./I would get up out of bed/ I would ask this person to leave/ and I would deal with it then./ I just don't understand the logic./ I mean I don't think that it's appropriate to get back into a bed with somebody who you claim was taking advantage of you./ 